\title{
A study of the factors associated with anxiety and depression among the patients of arthritis
}

\author{
Siddiqui F. ${ }^{1}$, Kumar A. ${ }^{2}$ \\ ${ }^{1}$ Dr. Faisal Siddiqui, Senior Resident, Department of Psychiatry, All India Institute of Medical Sciences, \\ Bhopal, ${ }^{2}$ Dr. Anoop Kumar, Associate Professor, Department of Medicine, Hind Institute of Medical Science, \\ Safidabad, Barabanki, U.P, India.
}

Address for Correspondence: Dr Anoop Kumar, Associate Professor, Department of Medicine, Hind Institute of Medical Science, Safidabad, Barabanki, U.P. E-mail: kanoopdr@gmail.com

\begin{abstract}
Background: Arthritis is one of the common chronic disease and leading cause of disability in India. Due to increasing number of older adults, the prevalence of arthritis is expected to rise dramatically. Depression and anxiety are generally more common among people with arthritis than in general population and interplay independently and synergistically with clinical outcomes such as pain and disability. Aim: To study the prevalence of depression, anxiety and the factors associated with them among Indian adults suffering from arthritis in a tertiary care centre. Material and Methods: The study sample comprised of adults age above 30 years with clinician diagnosed arthritis $(n=370)$. Depression and anxiety were measured using separate and validated scales. Prevalence was estimated for the sample overall and stratified by subgroups. Associations between correlates and each condition were estimated with prevalence ratios. Result: Depression was more common than anxiety ( $24 \%$ and $11 \%$ respectively) overall; about $8 \%$ of patients have mixed depression and anxiety disorder. Among them only $2-3 \%$ of patients seek consultation for mental health condition. Conclusion: Despite of high prevalence of depression and anxiety among the patients of arthritis help seeking for the psychiatric disability appears to be minimal. Untreated anxiety and depression may negatively impact on pain, mobility and quality of life.
\end{abstract}

Keywords: Arthritis, Anxiety, Depression

\section{Introduction}

Rheumatic and musculoskeletal conditions comprise over 150 diseases and syndromes which are usually progressive and associated with pain. They are the leading causes of morbidity and disability giving rise to enormous health care expenditure and loss of work. Estimated 350 million people worlds wide have arthritis [1]. These diseases which include such varied conditions as rheumatoid arthritis, osteoarthritis, gout, ankylosing spondylitis, psoriatic arthritis, systemic lupus erythymatosis and spondylo-arthropathies often cause severe pain and emotional suffering that may contribute to disability, interfere with physical mobility and declines in health related quality of life in many patients [2].

\footnotetext{
Manuscript received: $10^{\text {th }}$ July 2017

Reviewed: $20^{\text {th }}$ July 2017

Author Corrected: $29^{\text {th }}$ July 2017

Accepted for Publication: $4^{\text {th }}$ August 2017
}

Rheumatoid arthritis is a chronic systemic disease that affects joints, muscles, tendons and connective tissue. Its prevalence ranges from 0.3 to $1 \%$ in adults, affects 21 million and accounts for about 5 million DALY worldwide [3]. Osteoarthritis is a degenerative joint disease which mainly affects the particular cartilage. $10 \%$ of people above 60 years of age have symptoms of osteoarthritis. It is the $10^{\text {th }}$ leading cause of nonfatal burden in the world and accounts for 15 million DALYs globally [4].

Despite their slow development arthritis are progressive in nature and eventually lead to joint destruction, significant loss of function and reduced quality of life in many patients. Psychosocial factors are being suggested as mediators or moderators in the mediation of relation between arthritis and psychological functioning [5]. The 
prevalence of anxiety and depression in arthritis is higher than that of general population. In recent times large scale interest has been generated in the study of psychiatric and medical comorbidity in health service research and psychiatric epidemiology [6]. In India $15 \%$ of people i.e. 180 million suffer from arthritis the prevalence is higher than many well known diseases such as hypertension, diabetes, AIDS and cancer [7]. Inspite of the challenging and serious implications of psychological morbidity in relation to arthritis the field did not seem to attract the attention of mental health professionals.

The present study is planned to ascertain some basic data about the psychological concomitants of arthritis and their relation to sociobiographical, physical and medical factors.

\section{Materials and Methods}

It was a cross-sectional observational study conducted in a tertiary care health center in central India. 370 consecutive patients who had arthritis were selected as per inclusion and exclusion criteria. Institutional research and ethical committee approval was obtained prior to the study. Informed consent was obtained from each patient to participate in the study was obtained. Inclusion criteria is subjects between ages of 18 and 70 years and subjects diagnosed as suffering from various types of arthritis by orthopaedicians, rheumatologists and physicians and Exclusion criteria is patients with presence of psychosis, substance use disorders, and mental retardation.

Procedure: Sociodemographic and clinical data were obtained and meticulously documented on a specially prepared proforma. The following psychological instruments were used to obtain information about depression, anxiety and quality of life and pain in every case. Severity was graded by Physicians. The Investigator was not involved in the management of the cases.

1. Zung self rating depression scale: This is a 20 item self rating anxiety scale measuring cognitive, autonomic, motor and central nervous symptoms on a Likert scale ranging from 1 to 4 . It yields a maximum score of 80 and minimum 20. A cut off score of 45 used to identify anxiety [8].

2. Zung self rating anxiety scale: This is a self rating scale of depression having 20 items. Each item is measured on a scale 1 to 4 . The scale yields a maximum score of 80 . A cut off score of 45 is used to identify depression [9].

Statistical Analysis: Obtained data were subjected to statistical analysis using SPSS software version 20.0. Chi square test was used to compare qualitative data.

\section{Results}

In our study, out of total 370 cases of arthritis almost two thirds were females (64\%) and (36\%) were males. $78 \%$ were urban dwelling. $90 \%$ were married but a substantial number were widowed (8\%), 65\% were unemployed, $59 \%$ belonged to nuclear families. 55\% belonged to low economic status. Three quarters of the patients (75\%) had primary/secondary education. $60 \%$ of Rheumatoid Arthritis (RA) cases were below 50 years of age while $66.5 \%$ of Osteoarthritis cases were above 50 years of age. This difference in the age was statistically significant to a high degree. ( $\mathrm{X}^{2}$ value 36.5 and $\mathrm{P}$ value $\leq 0.000$ ). Distribution of the subjects according to the type of arthritis is shown in table no.1.

In the study subjects $24.3 \%$ had depression $11.3 \%$ had anxiety $8.1 \%$ had both anxiety and depression. Females suffered significantly more anxiety and depression than males. (Chi square value 14.5 and $p$ value $<0.002$ ) Widows were represented significantly high (33\% vs. 5-7\%) in those who suffered anxiety and depression (Chi square value 40.6 and $\mathrm{p}$ value $<0.000)$

Nuclear families were represented (86.7\% vs. 52-58\%) significantly high in those who suffered both anxiety and depression. (Chi square value 10.8 and $\mathrm{p}$ value $<0.013$ )

There is no significant depression between those who suffered anxiety and/or depression and those arthritis subjects who did not suffer from anxiety and depression in education ( $p$ value $<0.067$ ) income ( $p$ value $<0.104)$ employment status ( $\mathrm{p}$ value $<0.153$ ) and place of living ( $\mathrm{p}$ value $<0.141)$ 
Table No.-1: Distribution of the subjects according to the type of arthritis.

\begin{tabular}{|c|c|c|c|}
\hline Age & \multirow{5}{*}{$\begin{array}{c}\text { Rheumatoid arthritis } \\
9 \\
9 \\
10 \\
2\end{array}$} & \multirow{5}{*}{$\begin{array}{c}\text { Osteoarthritis } \\
14 \\
94 \\
114 \\
110\end{array}$} & \multirow{5}{*}{$\begin{array}{c}\text { Others } \\
1 \\
2 \\
4 \\
1\end{array}$} \\
\hline Less than 40yrs & & & \\
\hline $40-50$ & & & \\
\hline $50-60$ & & & \\
\hline \multirow[t]{2}{*}{ More than 60yrs } & & & \\
\hline & \multicolumn{3}{|c|}{ Chi square value 36.5 and $p$ value $<0.0001$} \\
\hline \multicolumn{4}{|c|}{ Gender } \\
\hline Male & \multirow{2}{*}{$\begin{array}{c}4 \\
26\end{array}$} & 128 & 2 \\
\hline Female & & 204 & 6 \\
\hline \multicolumn{4}{|c|}{ Chi square value 12.6 and $p$ value $<0.002$} \\
\hline Marital status & \multirow{5}{*}{$\begin{array}{c}28 \\
0 \\
1 \\
1\end{array}$} & \multirow{5}{*}{$\begin{array}{c}295 \\
7 \\
15 \\
15\end{array}$} & \multirow{5}{*}{$\begin{array}{l}5 \\
1 \\
2 \\
1\end{array}$} \\
\hline Married & & & \\
\hline Bachelor & & & \\
\hline Widowed & & & \\
\hline Divorced & & & \\
\hline \multicolumn{4}{|c|}{ Chi square value 10.6 and $p$ value $<0.102$} \\
\hline Family pattern & \multirow{3}{*}{$\begin{array}{l}12 \\
18 \\
\end{array}$} & \multirow{3}{*}{$\begin{array}{l}132 \\
200\end{array}$} & \multirow{3}{*}{$\begin{array}{l}2 \\
6 \\
\end{array}$} \\
\hline Nuclear & & & \\
\hline Extended & & & \\
\hline \multicolumn{4}{|c|}{ Chi square value 716 and $p$ value $<0.699$} \\
\hline Occupation & \multirow{3}{*}{$\begin{array}{c}8 \\
22\end{array}$} & \multirow{3}{*}{$\begin{array}{l}112 \\
270\end{array}$} & \multirow{3}{*}{$\begin{array}{l}1 \\
7 \\
\end{array}$} \\
\hline Employed & & & \\
\hline Unemployed & & & \\
\hline \multicolumn{4}{|c|}{ Chi square value 2.14 and $p$ value $<0.343$} \\
\hline
\end{tabular}

$53 \%$ of arthritis subjects who suffered anxiety were below 50 years of age while only $26 \%$ of depressed patients were below 50 years of age. $74 \%$ of the depressed groups were above 50 years of age while only $47 \%$ of the anxious groups were above 50 years of age. $53 \%$ of mixed anxiety and depression group also were below 50 years of age. These differences in age were highly significant (Chi square value 28.3 and $\mathrm{p}$ value $<0.001$ ). Distribution of the subjects according to the presence of anxiety and depression is shown in table no.2.

Table No.-2: Distribution of the subjects according to the presence of anxiety and depression.

\begin{tabular}{|c|c|c|c|c|}
\hline Gender & Anxiety & Depression & Mixed anxiety and depression & Normal \\
\hline Male & 12 & 26 & 4 & 90 \\
\hline Female & 30 & 64 & 26 & 118 \\
\hline \multicolumn{5}{|c|}{ Chi square value 14.5 and $p$ value $<0.002$} \\
\hline \multicolumn{5}{|c|}{ Marital Status } \\
\hline Married & 38 & 82 & 20 & 194 \\
\hline Bachelor & 2 & 0 & 1 & 1 \\
\hline Widowed & 2 & 6 & 8 & 12 \\
\hline Divorced & 0 & 2 & 1 & 1 \\
\hline \multicolumn{5}{|c|}{ Chi square value 40.6 and $p$ value $<0.0000$} \\
\hline \multicolumn{5}{|c|}{ Family Pattern } \\
\hline Nuclear & 22 & 50 & 26 & 120 \\
\hline Extended & 20 & 40 & 4 & 88 \\
\hline \multicolumn{5}{|c|}{ Chi square value 10.8 and $p$ value $<0.013$} \\
\hline \multicolumn{5}{|c|}{ Occupation } \\
\hline Employed & 18 & 28 & 6 & 78 \\
\hline Unemployed & 24 & 62 & 24 & 130 \\
\hline \multicolumn{5}{|c|}{ Chi square value 5.26 and $p$ value $<0.153$} \\
\hline \multicolumn{5}{|c|}{ Age Group } \\
\hline Less than 40 & 2 & 6 & 2 & 35 \\
\hline $41-50 y r s$ & 20 & 17 & 14 & 50 \\
\hline $51-60 y r s$ & 14 & 36 & 4 & 73 \\
\hline More than 60 yrs & 6 & 31 & 10 & 50 \\
\hline \multicolumn{5}{|c|}{ Chi square value 28.3 and $p$ value $<0.001$} \\
\hline
\end{tabular}




\section{Discussion}

In the present study $42.8 \%$ of the subjects were found to have anxiety and/or depression. $23.4 \%$ of the subjects had depression, $11.3 \%$ had anxiety and $8.1 \%$ had both anxiety and depression. Quite a substantial number of studies reported preponderance of anxiety, however the findings are in agreement with other studies $[10,11,12]$.

In the present study $8.1 \%$ had mixed anxiety and depression which is different from $(15.9 \%)$ which was reported by Isik et al [13], but similar to Murphy et al [14] who reported $8.4 \%$. It is not possible to discribe any cause for the discrepant results as different workers used different instruments and there could be many psychosocial, comorbid and other biological factors that underlay the phenomenon.

In the contrast present study females are seen to suffering more depression and anxiety which is conformity with the general trend. Stress may be playing a part in the occurrence of mixed anxiety and depression as $87 \%$ of them are from nuclear families in marked to $52-58 \%$ in depression and anxiety respectively. Further $33 \%$ of the mixed categories are widowers whereas only 5 to $7 \%$ of Anxiety and depressive categories are widowers. Loneliness of a widower from nuclear family could be one important factor contributing to the occurrence of anxiety and depression together besides other disease related factors.

The present study shows that relatively younger arthritic patients are prone to anxiety whereas older people are more prone to depression. This is in conformity with the findings of Murphy et al [14].

The present study will have limitations of a hospital based investigation as it may not reflect the picture at the population level. Also, instead of screening instruments structured interviews would have been useful in establishing clinical diagnosis. But considering the fact that depression and anxiety symptoms have as much effect on health-related quality of life as syndromal diagnoses this study can be considered to be of some value.

\section{Conclusion}

The present study has shown that nearly behalf of patients suffering from arthritis have undiagnosed psychological morbidity which will have adverse effects on function and quality of life. Identification of anxiety and depression in subjects suffering from arthritis will have definite implications for comprehensive management of patients. Effective management of anxiety and depression by drugs and psychotherapy is likely to improve the clinical picture, suffering and quality of life. Screening for anxiety and depression should form an essential part of the clinical workup of patients suffering from arthritis.

\section{Funding: Nil, Conflict of interest: None Permission of IRB: Yes}

\section{References}

1. Rheumatoid arthritis www.who.int/chp/topics/ rheumatic/in accessed on 14 Nov 2015.

2. Lokeshia A Sumner and Perry M Nicassio in: Perry M Nicassio. Ed Psychosocial Factors in Arthritis. Springer 2015).

3. Cross M, Smith E, Hoy D, Carmona L, Wolfe F, Vos T, Williams B, Gabriel S, Lassere M, Johns N, Buchbinder R, Woolf A, March L. The global burden of rheumatoid arthritis: estimates from the global burden of disease 2010 study. Ann Rheum Dis. 2014 Jul; 73 (7): 1316-22. doi: 10.1136/ annrheumdis -2013-204627. Epub 2014 Feb 18.

4. Osteoarthritis www.who.int/healthinfo/ statistics /bod_osteoarthrits accessed 21 Nov 2015.

5. Harris M L. Physical and clinical predictors. In: Perry M Nicassio. Ed Psychosocial Factors in Arthritis. Springer 2015.

6. DeVellis BM, DeVellis RF. Depression and arthritis. N C Med J. 2007 Nov-Dec;68(6):434-5.

7. Arthritis www.arthritis-india.com accessed on 15 Nov 2015.

8. Zung WW. A rating instrument for anxiety disorders. Psychosomatics. 1971 Nov-Dec; 12 (6): 371-9.

9. ZUNG WW. A self-rating depression scale. Arch Gen Psychiatry. 1965 Jan;12:63-70. 


\section{Original Research Article}

10. Takade T, Morimato N, Kinukewa $\mathrm{N}$ et al. Factors affecting depression and anxiety in female Japanese patients with rheumatoid arthritis. Clinical and Experimental Rheumatology. 2000; 5: 101-12.

11. el-Miedany YM, el-Rasheed AH. Is anxiety a more common disorder than depression in rheumatoid arthritis? Joint Bone Spine. 2002 May; 69 (3):300-6.

12. Zyrianova Y, Kelly BD, Gallagher C, McCarthy C, Molloy MG, Sheehan J, Dinan TG. Depression and anxiety in rheumatoid arthritis: the role of perceived social support. Ir J Med Sci. 2006 Apr-Jun;175(2):32-6.

13. Isik A, Koca SS, Ozturk A, Mermi O. Anxiety and depression in patients with rheumatoid arthritis. Clin Rheumatol. 2007 Jun; 26 (6):872-8. Epub 2006 Aug 29.

14. Murphy LB, Sacks JJ, Brady TJ, Hootman JM, Chapman DP. Anxiety and depression among US adults with arthritis: prevalence and correlates. Arthritis Care Res (Hoboken). 2012 Jul; 64 (7): 968-76. doi: 10.1002/acr.21685.

\section{How to cite this article?}

Siddiqui F, Kumar A. A study of the factors associated with anxiety and depression among the patients of arthritis. Int J Med Res Rev 2017;5(09):872-876.doi:10.17511/ijmrr. 2017.i09.07. 